\title{
CELESTE, A BONECA COM OLHOS VERDES DE ESPERANÇA: O IMAGINÁRIO INFANTIL DE SÓNIA SULTUANE ${ }^{1}$
}

Sávio Roberto Fonseca de Freitas

Para todas as crianças do mundo, esta lição de humanidade.

Resumo: O objetivo deste estudo é desenvolver uma análise da obra literária infantil Celeste, a boneca com olhos cor de esperança (2017), da escritora moçambicana Sónia Sultuane. Movida pela sensibilidade ocular desbravadora de mundos e de humanitarista declarada, Sónia Sultuane faz migrar a poesia para a literatura infantil. Joana é uma personagem infantil que representa o exercício da solidariedade, da saúde coletiva e da consciência humanitária. Ao contar esta estória, Sultuane mostra que o mundo contemporâneo está muito tóxico e a literatura é um caminho para o exercício da humanidade. Alguns aspectos são levados em consideração na análise: a oralidade, o humanitarismo e o imaginário infantil no feminino. Como suporte teórico, ancoramos nossas análises em posicionamentos de: (CANDIDO, 2011, p. 172). (CHEVALIER; GHEERBRANT, 2006, p. 653), (MOREIRA, 2005, p. 31), (BACHELARD, 1990. p. 6), (SECCO, 2007, p. 9-10) e (CHIZIANE\&MARTINS, 2018, p. 27).

Palavras-chave: Oralidade. Humanitarismo. Imaginário infantil no feminino.

Abstract: The aim of this study is to develop an analysis of the children's literary work Celeste, a boneca com olhos cor de esperança (2017), by Mozambican writer Sónia Sultuane. Moved by the eye-opening sensibility of worlds and a declared humanitarian, Sónia Sultuane moves poetry to children's literature. Joana is a child character who represents the exercise of solidarity, collective health and human conscience. In telling this story, Sultuane shows that the contemporary world is very toxic and literature is a way for the exercise of humanity. Some aspects are taken into account in the analysis: orality, humanitarianism and children's imagination in women. As theoretical support, we anchor our analysis in positions of: (CANDIDO, 2011, p. 172). (CHEVALIER; GHEERBRANT, 2006,

1 Título em língua estrangeira: “Celeste, a boneca com olhos verdes de esperança: Sónia Sultuaness child imaginary". 
p. 653), (MOREIRA, 2005, p. 31), (BACHELARD, 1990. p. 6), (SECCO, 2007, p 9-10) and (CHIZIANE \& MARTINS, 2018, p. 27).

Keywords: Orality. Humanitarianism. Children's imagination in the feminine.

\title{
Primeiras colocações
}

\author{
Essa força \\ Esta forma e força, \\ do começo, da entrega, \\ do dar, do querer, do receber, \\ liberta todos os sentidos, \\ os sentidos dos sentimentos, \\ quando tudo acaba, \\ fica só o estranho sentido e o sentimento do \\ vazio
}

(SULTUANE, 2006, p. 35)

Figura 1: Sónia Sultuane

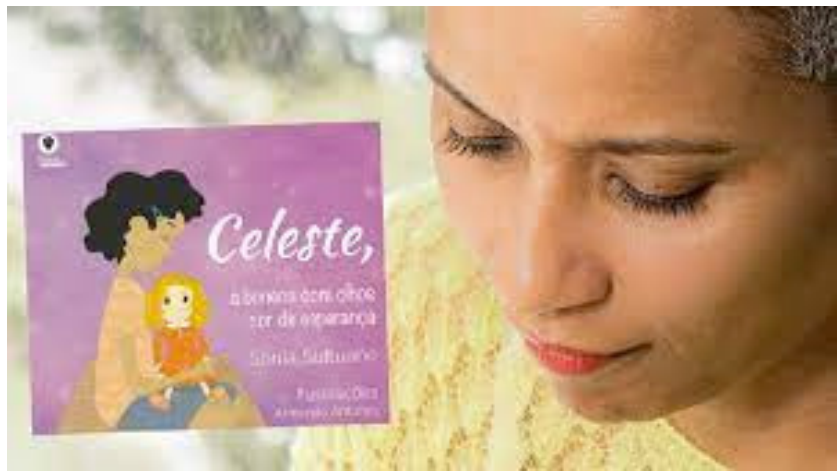

Fonte: www.jornaltornado.pt

Consagrada como poeta e artista plástica moçambicana, Sónia Sultuane também escreve literatura para crianças. As obras dedicadas ao público infantil são: A lua de N'weti (2014) e Celeste, a boneca com olhos cor de esperança (2017). Os 
livros são publicados pela Editorial Novembro, uma editora portuguesa, e ainda não há uma publicação brasileira, um dos motivos que podem ser causadores do pouco conhecimento dos leitores brasileiros sobre esta escolha de escrita da autora em tela.

Nosso objeto de análise será o livro Celeste, a boneca com olhos cor de esperança (2014). A narrativa infantil traz alguns aspectos que não podem passar desapercebidos: a oralidade que se faz presente no modus operandi da contação de estórias tão preservadas pelas mulheres moçambicanas e sempre defendida pela escritora Paulina Chiziane; o exercício de uma consciência humanitária partir do discurso de Joana; e a simbologia da boneca Celeste.

Figura 2: Livro Celeste

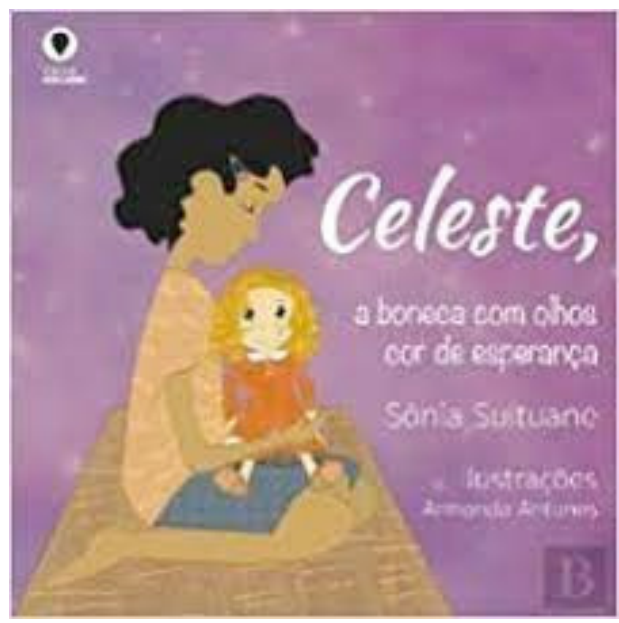

Fonte: www.amazon.com 
A narrativa trata da estória de Joana, uma oftalmologista, nascida na Suiça, porém filha de pais portugueses que emigraram para Genebra em busca de melhores condições financeiras. Os avós maternos de Joana ficaram em Portugal, guardando memórias e muitas saudades da neta. Para sanar a ausência da Joana, a avó mandou fabricar uma boneca parecida com a neta: cabelos loiros cacheados, bochechas com sardas e olhos bem verdes. O vestido da boneca era cor de cenoura para lembrar a neta a importância dos vegetais e, principalmente, que a cenoura era muita boa para a vista. Joana gostou tanto da boneca que a batizou com o nome da avó: Celeste.

Um dado relevante nesta narrativa infantil de Sónia Sultuane é o poder dos olhos. Os olhos verdes da boneca Celeste funcionam como um portal que faz a personagem Joana transitar da fase adulta para a infância e vice-versa, a partir de um exercício lúdico da movimentação das memórias afetivas. Celeste, além de ser o nome da avó materna de Joana, é um símbolo de uma infância vivida com amor, educação e humanitarismo. Logo, os olhos são elementos que perpassam toda a mensagem moral de desta narrativa:

O olho, órgão de percepção visual, é, de modo natural e quase universal, o símbolo da percepção intelectual. É preciso considerar, sucessivamente, o olho físico, na sua 
recepção da luz; o olho frontal - o terceiro olho de Xiva; enfim o olho do coração. Todos três recebem a luz espiritual. (CHEVALIER; GHEERBRANT, 2006, p. 653)

De acordo com o pensamento acima de Jean Chevalier e Allain Gheerbrant (2006, p. 653), podemos afirmar que Joana, enquanto personagem central do protagonismo da estória, representa a possibilidade de ser o mundo o olho do coração, ou seja, o olhar se torna uma estratégia especular de Sónia Sultuane fazer os leitores pensarem um mundo humanizado e fortalecido pelo afeto.

\section{Celeste e a lição de humanidade}

Na coletânea de poemas intitulada Imaginar 0 Poetizado (2006), Sónia dedica um especial exercício as sensações do olhar, o que pode se configurar com uma possível preocupação da escritora como os modos de se ver mundo e o medo de que tudo possa perder o sentido e a razão de ser.

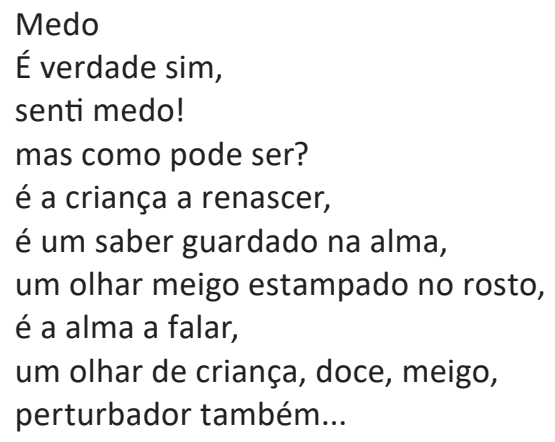




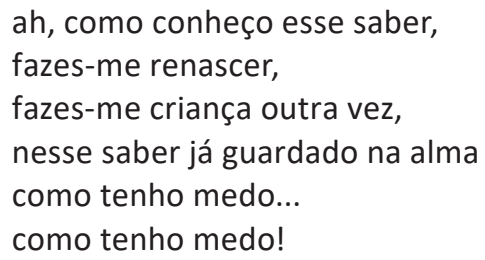

(SULTUANE, 2006, p. 25)

O poema acima nos mostra uma voz poética convidativa ao renascimento da criança, ou melhor, ao modo infantil de ver o mundo, algo que está em vias de extinção na contemporaneidade caótica na qual nós nos encontramos. As crianças são a nossa última oportunidade de tentar resolver os males do mundo, por isso precisamos saber educar assim como sugere o texto infantil de Sónia Sultuane, sem medo de deixar que as crianças renasçam dentro de nós, como bem chama a atenção a voz poética presente no poema acima, a qual faz da labuta literária um jogo lúdico entre o medo de ser e de renascer criança. Logo, percebemos que a narrativa infantil da poeta moçambicana continua a ouvir a voz poética dos poemas construídos sob a ordem de poder imaginar um mundo pela poeticidade:

$\mathrm{O}$ que faz a verdadeira poeticidade de um texto é que nunca ele obedece servilmente a quaisquer diretrizes racionais e teóricas, mas estabelece uma constante tensão com as mais amplas potencialidades da expressão, fazendo-as vir à tona no discurso. Ou seja: pensando apenas no campo estético, uma 
coisa é a argumentação teórica, outra coisa é a prática poética. Na primeira temos convenções e leis; na segunda, a liberdade de invenção. (CARA, 1998, p. 26)

A liberdade de invenção proporcionada pela prática poética é o que permite Sónia Sultuane, por meio da escrita literária, traçar caminhos imaginários que vão ganhando substância discursiva no corpo estético e ideológico da narrativa que toma forma sob a emergência de criar um texto ao alcance das crianças. A boneca Celeste, mesmo sem dizer uma palavra na narrativa, movimenta a circularidade das vozes da avó materna, de Joana e da menina Graça. Os nomes destas personagens carregam uma simbologia propositada. Celeste metaforizando o céu; Joana cumprindo a missão divina de curar e fazer ver o mundo; e Graça, a dádiva de ver a partir do coração. Personagens movidas pelas metamorfoses do olhar:

As metamorfoses do olhar não revelam somente quem olha; revelam também quem é olhado, tanto a si como ao observador. É com efeito curioso observar as reações do fitado sob o olhar do outro e observar-se a si mesmo sob olhares estranhos. O olhar aparece como símbolo e instrumento de uma revelação. Mais ainda, é um reator e um revelador recíproco de quem olha e de quem é olhado. O olhar de outrem é um espelho que reflete duas almas. (CHEVALIER; GHEERBRANT, 2006, p. 653) 
Trazer a metamorfose de olhar o mundo por meio de uma perspectiva infantil solidarizada é uma forma de apresentar um imaginário que ainda se mantém invisível na literatura em função de uma crítica literária ainda organizada por orientações excludentes e autorizadas por cânones sistematizados por princípios colonizados. Através de Joana, Sónia Sultuane nos dá um simulacro de como a humanização pode unir povos. Contar esta estória ao modo moçambicano é reviver o calor da fogueira sob o comando das vozes mais experientes:

Nos tempos antigos, os contos tradicionais fizeram parte da dinâmica cultural das sociedades africanas. Ouvir os mais velhos contadores de estórias, sentar à sombra das árvores sagradas e se embevecer com narrativas, cujos enredos e temáticas não separam os homens da natureza, eram práticas fundamentais que, entretanto, hoje, estão se perdendo. Na época ancestral, as idades da vida se completavam e a criança estava inserida no mundo dos adultos. (SECCO, 2007, p. 9)

Celeste, a boneca com olhos cor de esperança (2017) é uma narrativa infantil que recupera, como atesta Carmen Secco (2007, p. 9), a dinâmica cultural da sociedade moçambicana, quando nos dá dispositivos estéticos e ideológicos para perceber a tradição da contação de estórias, o exercício da 
humanização pelo contato com os dilemas do existir e o reconhecimento das forças que o regem, e, principalmente, a valorização de um humanitarismo que coloca em uma mesma linha comportamental as crianças e os adultos.

Figura 3 - Sónia Sultuane

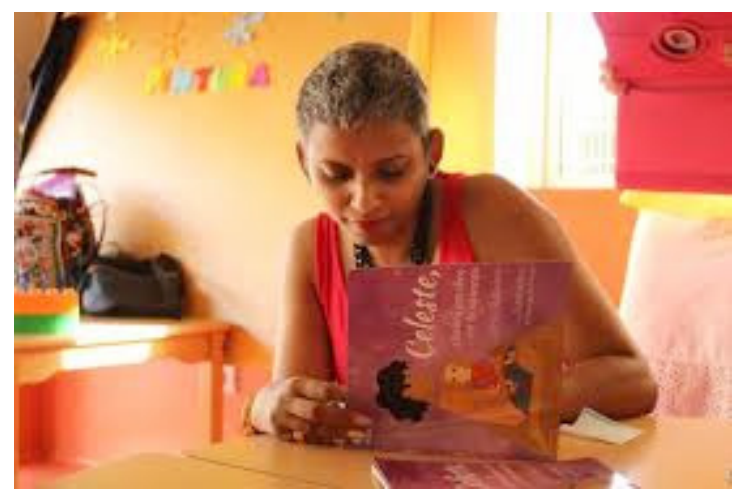

Fonte: www.soniasultuane.com

No universo moçambicano da contação de estórias, os fatos se organizam pela ordem da natureza e da ancestralidade. A voz dos ancestrais se confundem com a voz do narrador, um ser de papel que, no âmbito das literaturas africanas, torna-se um refém disponível às multifacetadas performances do ato de narrar sob às astúcias miméticas da oralidade. Como nos mostra Terezinha Taborda Moreira (2005, p.31): "Todo ato de narrar instala sua perspectiva logo nas primeiras linhas. Isso torna evidente que a adoção de um modo de narrar corresponde a uma intenção deliberada do narrador". 
Concordamos com Terezinha Taborda Moreira (2005, p. 31) no que se refere ao modo de narrar que se apresenta nas primeiras linhas como algo intencional do narrador. No texto literário em análise, Sónia Sultuane claramente se apropria do modo karinguana ua karingana, prática ronga da contação de estórias em volta da fogueira. Não se pode deixar de mencionar que toda estória contada sob esta perspectiva possui um fim moralizante e educador em relação à cultura local.

Era uma vez uma médica oftalmologista chamada Joana. Por ser oftalmologista, a sua especialidade era tratar a doença dos olhos, ou seja, devolver a visão ou corrigir os seus distúrbios.

A Joana nasceu na Suíça, em Genebra, porque os seus pais tinham emigrado à procura de melhores condições de vida. A mãe também era médica: era ortopedista, tratava de problemas relacionados com os ossos; e o pai trabalhava num banco.

A Joana cresceu, estudou e formou-se na Suíça. Toda a vida viveu no país dos mais famosos chocolates do mundo. (SULTUANE, 2017, p. 6)

Como toda estória que se conta para um público ouvinte, a narração aqui exposta nos lança para o mundo imaginário de Joana, uma menina notadamente privilegiada por ter nascido em país que funciona enquanto estado político. Um outro dado importante que se volta ao universo de Joana é a 
ambientalização que envolve a personagem (cresceu, estudou e formou-se na Suíça). Estes aspectos se constituem como elementos que nos fazem questionar por que uma escritora moçambicana privilegia em sua narrativa uma personagem eurocentrada e declaradamente formada por um território economicamente desenvolvido, o que pode ser incompatível com a realidade das crianças moçambicanas.

Figura 4 - Crianças Moçambicanas

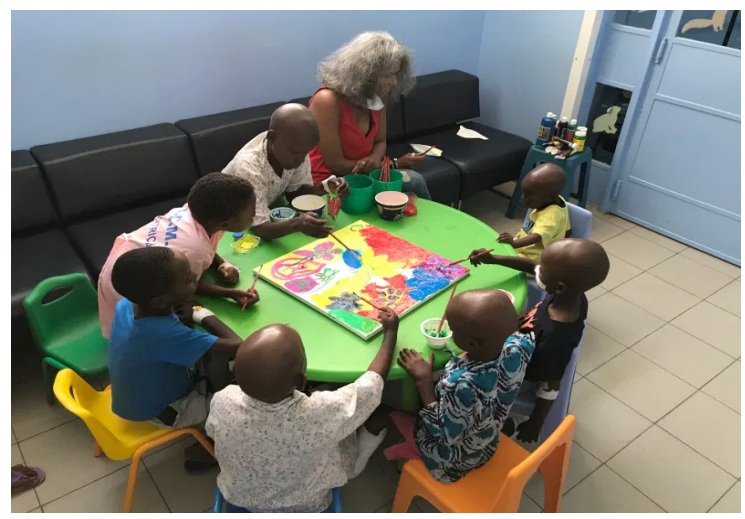

Fonte: www.soniasultuane.com

A descrição e a disposição das sentenças confirmam a presença da oralidade no registro escrito por meio da expressão Era uma vez, sentença que conduz muitas crianças para viajar ao mundo das tantas possibilidades do imaginário infantil. Sónia Sultuane, logo no primeiro momento da narrativa infantil, deixa visível a poeticidade, a sensibilidade e a preocupação com a organização do 
feminino, o que nos faz mais uma vez concordar Terezinha Taborda Moreira (2005, p. 31), quando a pesquisadora afirma que todo modo de narrar é intencional. A partição da avó materna na narrativa é intencional no sentido estabelecer que aos velhos cabe o discurso da sabedoria.

Os avós maternos de Joana tinham muitas saudades suas, principalmente a sua avó, pois a Joaninha, como ela gostava de chamar, era a sua única neta.

Como viviam num outro país, em Portugal, e para que Joaninha nunca se sentisse sozinha, a vó mandou fabricar uma boneca especial para oferecer à neta. Mandou fazer um vestido cor de cenoura, cor de laranja, para que ela lembrasse de comer vegetais, principalmente cenouras, "para ter olhos bonitos", e assim colocar beleza na vida das pessoas, todas as vezes que as olhasse. Pediu que a boneca tivesse cabelos loiros, muito cacheados, iguais aos da Joaninha, quando ele era pequenina; umas bochechas com sardas pequenininhas e olhos verdes e brilhantes, iguais aos seus, para que a neta nunca se esquecesse dela.

A Joana amava tanto, mas tanto, aquela boneca que the deu o nome da sua avó: Celeste. (SULTUANE, 2017, p. 9)

Trazer uma menina nascida em um país europeu como personagem principal de uma narrativa infantil é uma estratégia também política, uma vez que se dá, por meio da literatura, a oportunidade de discutir direitos humanos. 
A boneca Celeste tem uma funcionalidade muito relevante na narrativa. Celeste representa o amor da avó, a infância de Joana, a lembrança dos avós portugueses, a circularidade dos afetos na narrativa, a educação familiar, um modo de ver o mundo por uma perspectiva humanizada, ou seja, o direito humano de ser criança e de crescer sem esquecer todas fases de amadurecimento. Os pais de Joana preservam estes valores e direitos. A Suíça é um território onde se preserva a qualidade de vida em seus aspectos de raça, classe e gênero; ou seja, é mostrar as crianças moçambicanas que o humanitarismo independe da nação. É preciso uma tomada de consciência em relação aos direitos humanos.

Por quê? Porque pensar em direitos humanos tem um pressuposto: reconhecer que aquilo que consideramos indispensável para nós é também indispensável para o próximo. Esta me parece a essência do problema, inclusive no plano estritamente individual, pois é necessário um grande esforço de educação e auto-educação a fim de reconhecermos sinceramente este postulado. Na verdade, a tendência mais funda é achar que os nossos direitos são mais urgentes que os do próximo. (CANDIDO, 2011, p. 172)

Concordamos com Antonio Candido (2001, p. 172) quando precisamos pensar no próximo, deixarmos o egoísmo de lado e humanizar de forma globalizada os nossos 
sentimentos mais urgentes de solidariedade. Oportuno é pensar o quanto é tóxico o egocentrismo elitista tão exercitado pelas classes favorecidas pelas convenções de raça, classe e gênero. Nesse sentido, é salutar mostrar o personagem Padre António:

Certo dia, o padre António, num domingo de Páscoa, apareceu na casa de Joana, já ela era quase doutora. Estava de visita rápida, tinha ido a vários países da Europa, em missão, para arranjar donativos para a reconstrução de um hospital onde estava a trabalhar, em Moçambique, muito perto de Maputo. Estava eufórico, como sempre, e entusiasmado com o projeto. Os moçambicanos eram um povo afetuoso, por isso trazia ele muitos projetos e sonhos a concretizar. (SULTUANE, 2017, p. 10)

A presença do padre António nesta narrativa é reveladora porque nos oferece algumas possibilidades de interpretação: o padre surge em um momento de Páscoa, portanto de reforço de afetos familiares, da memória de infância e da epifania da boneca Celeste para a vida de Joana, a qual vai se seduzir pelo projeto social do padre e vai descobrir um Moçambique tão carente de ajuda clínica e social. Os olhos de Celeste, a esperança de ver um mundo melhor, são a prolepse de uma revelação humanitária nesta narrativa. Nesse sentido, Sónia Sultuane nos atenta mais 
uma vez para o hibridismo cultural tão marginalizado por alguns moçambicanos e aqui colocado como um dilema em uma mesma linha de reflexão para crianças e adultos, os quais precisam se educar para a solidariedade humanitária que só realizável quando a conscientização em prol dos direitos humanos extrapola os limites repressores das relações de raça, classe e gênero. Sultuane nos faz entender que educar as crianças para a leitura de mundos é um caminho rentável para o humanitarismo, pois as palavras quando andam...

desempenham um papel em nossa vida. Vitalizam-nos. Por elas, a palavra, o verbo, a literatura são promovidos à categoria da imaginação criadora. O pensamento, exprimindo-se numa linguagem nova se enriquece, ao mesmo passo que enriquece a língua. O ser torna-se palavra. A palavra aparece no cimo psíquico do ser. A palavra se revela como devir imediato do psiquismo humano. (BACHELARD, 1990. p. 6)

Em direção análoga ao pensamento do filósofo francês Gaston Bachelard (1990, p. 6), confirmamos que a literatura infantil de Sónia Sultuane, apropriando-se da categoria da imaginação criadora, desenvolve, por meio do discurso de Joana, uma narrativa infantil educadora e necessária à propagação do exercício humanitarista. Enquanto oftalmologista, Joana também deve exercer a profissão em 
prol de causas sociais. Por ser de uma elite privilegiada, ou seja, formada em um estado político e econômico que funciona, fica a sugestão de que a solidariedade é um exercício minimizador das diferenças:

A Joana ficou comovida com a missão do Padre António. Não hesitou e resolveu entregar-Ihe o seu baú, dizendo-lhe:

-Tenho certeza absoluta de que terá verdadeiramente mais utilidade e valor em África. Leve, Padre, será para mim uma honra e um privilégio ajudar esses meninos. (SULTUANE, 2017, p. 13)

Esta passagem confirma a quase obrigatoriedade sinalizada por Antonio Candido (2001, p.172) no que toca a questão da auto-educação sobre os direitos humanos, ou seja, é preciso sair da zona de conforto dos privilégios e abrir o baú da humanização, assim como o faz a Joana, quando menciona a ideia de valor em consonância com o entusiasmo de padre António em ajudar as crianças moçambicanas a viver a infância com brinquedos rememorativos de uma menina criada sempre com afeto, educação e estrutura social. Uma estratégia sutil, mas não ingênua, da escritora Sónia Sultuane de nos faz entender uma possível crítica ao modo de narrar e de pensar estabelecido pelos olhos da colonização portuguesa.

O colonialismo, as lutas de independência, os problemas oriundos das guerras civis provocaram sérias modificações na arte 
de narrar. Com a liberdade conquistada, tornou-se importante ensinar crianças e jovens a colocarem dentro de seus universos imaginativos o real das lutas guerrilheiras. (SECCO, 2007, p. 9-10)

A importância de ensinar jovens e crianças a colocar no universo imaginário as diversas possibilidades de representação simbólicas e ideológicas das guerras em Moçambique, como indica Carmen Secco (2007, p. 9-10), atesta a astúcia de Sónia Sultuane em optar por narrar para o público infantil a estória de uma menina loira e de olhos verdes, criada com todos os confortos de um país desenvolvido. A solidariedade é uma missanga fortalecedora deste fiar narrativo a que Sónia Sultuane se propõe:

Uns meses mais tarde, recebeu uma chamada do Padre António. Ele pedia-Ihe novamente ajuda. Precisava de médicos oftalmologistas porque, cada vez mais, chegavam ao hospital muitos meninos com problemas nos olhos, essencialmente cegueira.

A Joana era cirurgiã oftalmologista e exercia há já meio ano, com algum êxito em muitas cirurgias que realizara. Partiu para África, sem hesitar, levando com ela as suas mãos e os seus conhecimentos para tentar ajudar aqueles meninos.

Quando chegou no hospital, deparou-se com um cenário assustador. Foi levada, por uma enfermeira, até à sala onde estavam as crianças que ela devia ver e operar. Eram dezenas de crianças. (SULTUANE, 2017, p. 14) 
Essa passagem é muito importante na narrativa. A partir deste momento, Joana começa a perceber a proporção do trabalho de padre António e o quanto sua formação vai ser útil para as crianças moçambicanas ao ponto de ela entender e repensar valores sociais tão delimitados pelas questões de raça e classe. Não poder ver e devolver a visão para as crianças moçambicanas são dilemas enfrentados pela oftalmologista suíça em um território moçambicano, colonizado por Portugal, país de seus avós maternos, os quais tanto ensinaram que a visão é uma dádiva quando bem utilizada. O quanto a colonização portuguesa prejudicou os moçambicanos?

O colonialismo em África promoveu a superioridade de tudo o que era proveniente das antigas potências. Esta superioridade não permitiu dialogar, nem escutar, a voz do Continente Africano. Em nome da construção do mundo se fez a usurpação do ter; a África foi dividida em colônias, pela Conferência de Berlim. As crenças e as religiões foram abaladas. As várias instituições foram destruídas. A arte de cura e a religião tradicional foram perseguidas, proibidas, perseguidas, os praticantes mortos e escravizados. (CHIZIANE; MARTINS, 2018, p. 27)

Inegavelmente, em concordância com Paulina Chiziane e Mariana Martins (2018, p. 27), nunca podemos negar o quanto uma colonização invasiva é nociva aos 
pertencimentos culturais de um povo. Confirmamos então o quanto a narrativa infantil de Sónia Sultuane dialoga com a proposta de visibilidade em vários aspectos: ver o mundo; ver as diferenças de raça, classe e gênero; reconhecer o valor da solidariedade; confirmar a importância dos afetos; promover uma infância saudável; entender o quanto podemos contribuir com a formação das crianças; e, inegavelmente, acreditar que a nossa esperança de mundo mais justo só será possível se soubermos educar os pequenos.

A um canto estava uma menina sentada em uma esteira, perto de um amontoado de brinquedos, estava uma menina sentada de costas para a porta. A Joana aproximou-se e ajoelhou-se na esteira, bem pertinho dela, em silêncio. $E$ antes que ela pudesse dizer qualquer coisa, a menina voltou-se e pediu-lhe:

- Podes, por favor, dizer-me como é a minha boneca? Ela é a minha melhor amiga. Desde que ela chegou ao hospital, nos últimos meses, eu nunca mais senti sozinha... estou quase cega, só a sinto, mas queria tanto vê-la! A Joana olhou para o colo da menina e ficou sem fôlego. Com os olhos inundados de água, respondeu-Ihe:

Ela se chama Celeste, tem um vestido cor de cenoura, cabelos cacheados loiros. (SULTUANE, 2017, p. 17)

A passagem acima nos dá muitos caminhos de reflexão, mas o momento da epifania de Joana é um aspecto que 
não pode ser desconsiderado, pois permite confirmar alguns aspectos relevantes sobre a narrativa infantil de Sónia Sultuane: a circularidade da contação de estórias moçambicanas (a boneca que mata a saudade de Joana é a boneca faz a personagem Graça continuar a acreditar que pode voltar a enxergar); o ambiente moçambicano se apresenta por meio da esteira, sentar na esteira é um hábito de comunidades menos favorecidas (Joana ao chegar perto de Graça, percebe o quanto a sensibilidade da menina é aguçada; ajoelhar neste momento é um ato simbólico muito significativo para a narrativa porque fortalece a ideia de humanização por meio da aproximação e da solidariedade); e a reminiscência de Joana por meio da boneca Celeste (a boneca representa a importância do afeto).

E a menina perguntou:

- E os olhos? E os olhos?

- Os olhos são brilhantes e de cor verde. Como te chamas?

- Chamo-me Graça.

- Graça, prometo que te ajudarei a recuperares a tua visão para que possas ver a cor e o brilho dos olhos de Celeste.

Desde esse dia, a Joana nunca mais abandonou o hospital.

A Celeste, ainda hoje, continua com os olhos verdes e brilhantes a incentivar e a dar esperança a todos os meninos que ali chegam, para serem tratados. 
Um dia, a Joana sonhou que aquele hospital se chamava Hospital Verde Esperança! (SULTUANE, 2017, p. 18)

A narrativa finaliza com uma mensagem muito sábia de Sónia Sultuane. Uma mensagem de esperança para um mundo em que as pessoas não se enxergam mais como humanas. Joana representa a solidariedade tão esperado em tempos tão tóxicos e caóticos. Celeste personifica e materializa o afeto que deve perseguir uma criança em seus estágios de evolução social e espiritual. Graça nos mostra que mundo também pode ser visto e sentido pelo tato, pelo toque. Tocar as coisas assumiu uma importância tremenda na contemporaneidade dos tempos. Sónia Sultuane, com esta narrativa, nos comprova que a humanidade precisa de cura e a literatura pode ser um remédio bem sucedido. As palavras também andam quando extrapolam os limites da literatura e alcançam a recepção de crianças que veem na arte a possibilidade de criar um mundo melhor e humanitário, mesmo que o cenário nos conduza a um pensamento pessimista e desacreditado na evolução humana. 


\section{Últimas considerações}

Figura 5 - Responsabilidade Social

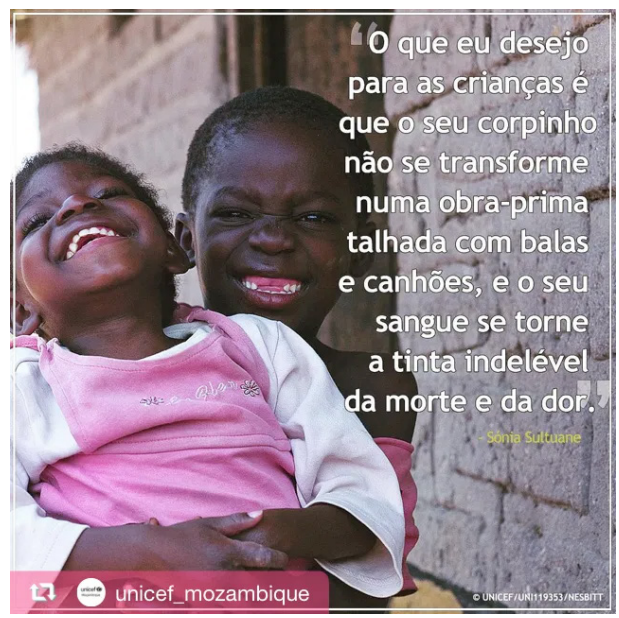

Fonte: www.soniasultuane.com

É oportuno também aqui mencionar que a escritora Sónia Sultuane possui projetos sociais em Moçambique. Estes projetos estão vinculados notadamente ao Projeto Walking Words. Este projeto foi iniciado pela escritora em 2008 e já se encontra publicado em formato digital na plataforma da Amazon. Houve muitas tentativas de publicação deste livro, mas as editoras com políticas questionáveis impediram a escritora de publicar a edição impressa do referido livro.

Os projetos sociais de Sónia Sultuane estão ligados a ações voltadas para crianças com câncer. Suas ações são desenvolvidas no Hospital Central de Maputo. A estória de Joana e a presença da menina Graça na narrativa podem 
ter sido motivadas pelas atividades desenvolvidas por estes projetos. A contação de estórias é uma das atividades desenvolvidas para as crianças moçambicanas hospitalizadas na Oncologia do Hospital Central de Maputo. Com a pandemia COVID-19 que fez o mundo parar, a preocupação da escritora só aumentou. Moçambique ainda é um país com poucos médicos preparados para lidar com o câncer e com os pacientes sequelados com a pandemia, por isso Sónia Sultuane também faz de sua arte um modo de curar e sanar a dor dos pacientes do referido hospital.

Figura 6 - Contando estórias

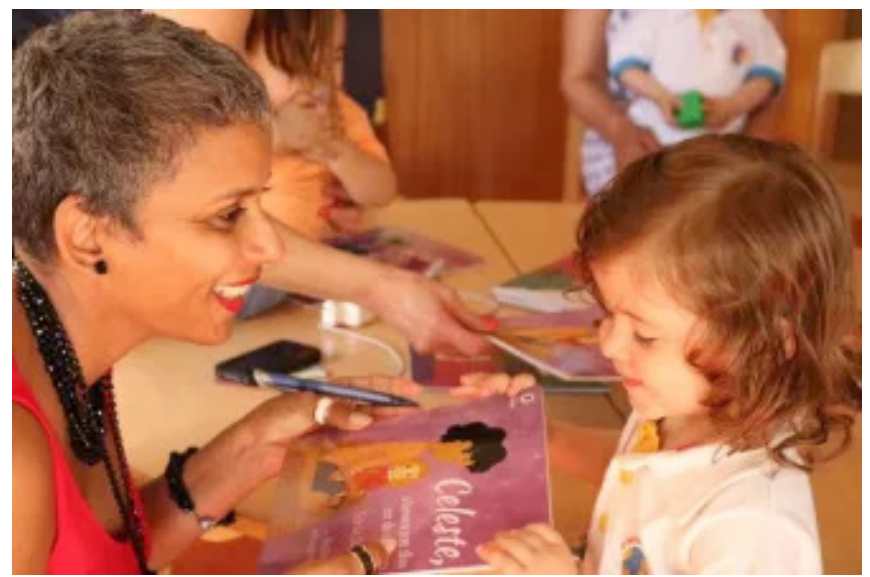

Fonte: www.soniasultuane.com

Celeste, a boneca com olhos cor de esperança é uma narrativa infantil de Sónia Sultuane que cumpre o compromisso assinalado por Carmen Tindó $(2007$, p.9) de educar crianças e jovens a pensar a nação moçambicana por 
meio de uma consciência política e humanizada em relação às tantas guerras ainda promovidas pelas centralizações eurocentradas e coloniais. Confirma o posicionamento de Terezinha Taborda Moreira (2005, p.31) em se mostrar uma narrativa que anuncia novas modalidades de narrar, fazendo do karingana ua karingana um modus operandi narrativo peculiar ao universo de contação de estórias moçambicano. Corrobora com o modo de ver o mundo que Gaston Bachelard (1990, p.6) chama de movência do imaginário em função de uma linguagem organizada para interferir na psique humana.

E vai muito mais além, quando confirma que a literatura é um direito da humanidade, como bem assinala Antonio Candido (2011, p.172). Um direito que nos ensina a olhar para outro sem egoísmos, sem preconceito e sem segregação. A narrativa infantil de Sónia Sultuane nos mostra o quanto podemos ajudar o mundo a se enxergar, a dar as mãos, a perceber que o único caminho para o aprimoramento físico, intelectual, e espiritual é a educação. Portanto sigamos todos juntos e de mãos dadas, acreditando que os olhos verdes de Celeste continuam a brilhar, dando esperança para aqueles que acreditam que o mundo contemporâneo pode ser curado pelo humanitarismo solidário e corporativista.

Karinguana ua Karingana... Karingana !!!!!! 


\section{Referências}

CARA. Salete de Almeida. A poesia lírica. São Paulo: Ática, 1998.

BACHELARD, Gaston. A terra e os devaneios do repouso: ensaios sobre as imagens da intimidade. Tradução de Paulo N. da Silva. São Paulo: Martins Fontes, 1990.

CANDIDO, Antônio. Vários escritos. 5. ed. Rio de Janeiro: Ouro Sobre Azul, 2011.

CHEVALIER, Jean; GHEERBRANT, Alain. Dicionário de símbolos. Rio de Janeiro: José Olympio, 2006.

CHIZIANE, Paulina; MARTINS, Mariana. Ngoma Yethu: o curandeiro e o Novo Testamento. Belo Horizonte: Nadyala, 2018.

MOREIRA, Terezinha Taborda. O vão da voz: a metamorfose do narrador na ficção moçambicana. Belo Horizonte: Editora Puc Minas, 2005.

SECCO, Carmen Lucia Tindó. Ensaios sobre Literatura Infantil de Angola e Moçambique: entre fábulas e alegorias. Rio de Janeiro: Quartet, 2007.

SULTUANE, Sónia. Imaginar o poetizado. Maputo: Ndjira, 2009.

SULTUANE, Sónia. A Lua de N'weti. Santo Tirso: Editorial Novembro, 2014.

SULTUANE, Sónia. Celeste, a boneca com olhos cor de esperança. Santo Tirso: Editorial Novembro, 2017.

\section{Sávio Roberto Fonseca de Freitas}

Doutor em Literatura e Cultura pela UFPB.

Professor de Literaturas de Língua Portuguesa no Departamento de Letras do CCAE-UFPB (Campus IV-Mamanguape) e do PPGL-UFPB (Campus I-João Pessoa).

Líder do Grupo de Pesquisa MOZA (Moçambique e Africanidades), cadastrado no CNPq e certificado pela UFPB.

E-mail: saviorberto1978@yahoo.com.br

Lattes: https://lattes.cnpq.br/6320246955492429

ORCID iD: http://orcid.org/0000-0001-7541-3377 